\title{
O olhar distanciado de Camilo e a quebra da catarse
}

Luciene Marie Pavanelo

Apesar de sua imensa produção, que engloba 137 títulos distribuídos em 180 volumes escritos durante quatro décadas dedicadas à literatura, Camilo Castelo Branco acabou se tornando metonimicamente sinônimo de Amor de Perdição (1862), romance considerado por grande parte da historiografia literária e mesmo por muitos especialistas como "o seu mais excelente romance" (CARVALHO, 2003, p. 352).

Segundo Fidelino de Figueiredo, em Literatura Portuguesa, "Amor de Perdição é a sua obra prima nesta maneira sentimental [...]. O romance camiliano é a quinta essência do lirismo passional, servido pelo maravilhoso do enredo" (FIGUEIREDO, 1941, p. 283). Jacinto do Prado Coelho, por sua vez, considerado um dos mais importantes camilianistas, aponta na Introdução ao Estudo da Novela Camiliana que "a novela amorosa era, pois, o seu domínio" (COELHO, 2001, p. 239), e que Amor de Perdição seria "uma obra-prima do gênero [...], com alguma coisa do sublime de Romeu e Julieta e do trágico de Manon Lescaut" (COELHO, 2001, p. 260). Para o crítico, "a novela camiliana é, pois, uma novela de aventuras, para recrear a imaginação, e de conflitos dramáticos, para fazer vibrar a sensibilidade" (COELHO, 2001, p. 393).

António José Saraiva e Óscar Lopes, autores da clássica História da Literatura Portuguesa, afirmam que a "figuração romanesca [camiliana] de uma dada concepção de vida fez correr imensas lágrimas às nossas avós ou trisavós. O leitor mais sofisticado de hoje sente-se, pelo contrário, inibido porque se apercebe muito melhor de certos cordelinhos de organização romanesca ou de linguagem enraizados na sensibilidade de outra época" (SARAIVA; LOPES, 1996, p. 791). Para os autores, no entanto, "se impõe, através de toda essa utensilagem datada e caduca, qualquer coisa de muito importante que em dados momentos a transcende e ainda hoje comove": o amor (SARAIVA; LOPES, 1996, p. 791). João Soares Carvalho, na recente História da Literatura Portuguesa (2003), arremata a visão canônica da obra camiliana com a seguinte afirmação:

\footnotetext{
Camilo não tem obras de grande profundidade [...]. Tendo de escrever para viver, não teve tempo para fazer uma boa e desejável observação das pessoas e das coisas, usando apenas a sua genial imaginação, subordinada a temas corriqueiros, folhetinescos, que ia repetindo, numa lamentável monotonia. (CARVALHO, 2003, p. 389)
}

Se podemos questionar a escolha de Amor de Perdição como eixo central para a compreensão da obra de Camilo, uma vez que sua vasta produção possui uma diversidade de temas e tratamentos estilísticos, também podemos discutir a leitura usualmente feita desse romance, que acaba ditando a visão que temos do escritor português. O enfoque dado ao sentimentalismo e à tragédia passional parece-nos ser resultado da cristalização da imagem de sua ficção como mero folhetim romântico, literatura de consumo produzida apenas para o deleite do público e, portanto, sem a complexidade que envolveria a leitura dos autores mais valorizados pelo cânone. 
José Ramos Tinhorão aponta a influência do melodrama na técnica do folhetim, que levou "a então recente criação do romance romântico a descer ao povo, para transformar-se na primeira expressão ficcional realmente de massa da era moderna" (TINHORÃO, 1994, p. 9). Entre as características transpostas ao folhetim, destacamos a apresentação "não [de] situações que levassem a pensar ou exigissem algum nível de informação paralela, mas [de] ações mirabolantes e situações patéticas" (TINHORÃO, 1994, p. 8). Assim, o romance romântico incorporou esse procedimento estético, "em conseqüência do tipo especial de exercício literário que era o de escrever (às vezes por encomenda) para um público cujos interesses e expectativas deviam ser respeitados" (TINHORÃO, 1994, p. 11).

Anatol Rosenfeld explica que o fim último do drama - gênero do qual derivou o melodrama - é a "descarga das emoções pelas próprias emoções suscitadas" (ROSENFELD, 2006, p. 33), ou seja, a catarse, motivada a partir de uma ação "rigorosamente encadeada, precipitando-se com terrível tensão para o desfecho, a ponto de sugar o espectador para o vórtice do seu movimento inexorável, sem lhe dar folga para observar, criticar, estudar" (ROSENFELD, 2006, p. 156). Algo que no folhetim romântico se aproximaria da catarse teatral seria o clímax conduzido pela tensão dramática, que produziria no ato de leitura um efeito semelhante ao das lágrimas incitadas pela encenação.

A imagem comumente tida do romance camiliano aproxima-se dessa definição de folhetim romântico, de traços melodramáticos, resumida nos elementos que o escritor apontou no prefácio da segunda edição de Amor de Perdição como responsáveis pelo sucesso de sua obra: "a rapidez das peripécias, a derivação concisa do diálogo para os pontos essenciais do enredo, a ausência de divagações filosóficas, a lhaneza da linguagem e desartifício das locuções" (CASTELO BRANCO, 1984, p. 378). Porém, como Paulo Franchetti (2003, p. XIX) percebeu, na mesma passagem Camilo afirma que "não aprov[a] a qualificação", desprezando o uso dessas características: "O romance que não se estribar em outras recomendações mais sólidas, deve ter uma voga mui pouco duradoura" (CASTELO BRANCO, 1984, p. 378). A partir dessa afirmação, o autor parece querer nos alertar que o seu romance é mais do que aparenta: apesar de fazer uso das técnicas do folhetim melodramático, a sua obra não é só isso.

Curiosamente, em As Modernas Idéias na Literatura Portuguesa, publicado em 1892, Teófilo Braga havia notado a onipresença da comicidade na ficção camiliana - "na sua obra predomina aquela tendência sarcástica" (BRAGA, 1892, p. 270) -, mas a vê como um empecilho para que se reconheçam as qualidades do que ele considera "criações que exprimem a pureza do sentimento" (BRAGA, 1892, p. 278). Braga defende que, "embora seja este [a forma satírica da arte] um dos aspectos mais salientes do seu gênio, com que assinalou a sua força e se impôs, essa capacidade estética, mais destinada a demolir do que a construir, não deixou reconhecer bem as grandes qualidades orgânicas de que dispunha” (BRAGA, 1892, p. 272).

A nosso ver, no entanto, o cômico em Camilo não seria um defeito, mas, misturado ao tratamento sério das questões sócio-culturais do período, consistiria numa das principais qualidades do seu romance e, para nós, aquilo que o tornaria atraente aos olhares do leitor atual, apesar de "toda essa utensilagem datada e caduca", para usar as palavras de Saraiva e Lopes. 
Segundo Rosenfeld, o cômico “produz certa 'anestesia do coração' momentânea, exige no momento certa insensibilidade emocional [...]. Para podermos rir [...], é impositivo que não fiquemos muito identificados e nos mantenhamos distanciados em face dos personagens e dos seus desastres" (ROSENFELD, 2006, p. 157). Assim, quando a tensão dramática começa a ser criada, deparamo-nos com um momento anticlímax, que impede que nossas lágrimas sejam derramadas. De acordo com António Cabral,

[...] um dos conseguimentos deste escritor é ir iludindo o pobre mortal que o lê, metê-lo por inteiro na embrulhada das suas histórias, adormecê-lo, saber que isso é mesmo assim e depois pregar-lhe um beliscão, como quem diz: acorde, amigo, se quer divertir-se com a leitura e, ao mesmo tempo, aprender alguma coisa com ela. (CABRAL, 1993, p. 53)

Sem dúvida, a tragédia passional e o sentimento moldam a temática principal de Amor de Perdição, que conta a triste história de amor entre Simão Botelho e Teresa de Albuquerque, cujas famílias eram inimigas e contrárias ao seu relacionamento. Abalada pelo assassinato de seu primo e pretendente, cometido pelo protagonista, e por sua conseqüente prisão e condenação, Teresa morre no convento, enquanto Simão morre a caminho do degredo, acompanhado de Mariana, que o ajuda e que, apaixonada por ele, acaba se suicidando. Em meio a essa atmosfera trágica, porém, abundam exemplos de cenas cômicas, das quais citaremos algumas.

No momento em que Simão é condenado à forca, no qual o narrador dá voz a personagens figurantes - os populares que estavam assistindo ao julgamento -, encontramos uma cômica crítica social, na denúncia dos privilégios da nobreza, diminuindo o processo de identificação com o herói e quebrando a tensão dramática:

- Quando vai ele a padecer?

- É bem feito! Vai pagar pelos inocentes que o pai mandou enforcar.

- Queria apanhar a morgada à força de balas!

- Não que estes fidalgos cuidam que não é mais senão matar!...

- Matasse ele um pobre, e tu verias como ele estava em casa!

- Também é verdade!

- E como ele vai de cara no ar!

- Deixa ir, que não tarda quem lha faça cair ao chão!...

- Dizem que o carrasco já vem pelo caminho.

- Já chegou de noite, e trazia dous cutelos numa coifa.

- Tu viste-o?

- Não; mas disse a minha comadre que lho dissera a vizinha do cunhado da irmã, que o carrasco está escondido numa enxovia. (CASTELO BRANCO, 1984, p. 481-482)

A crítica anticlerical, por sua vez, encontra terreno fértil na passagem em que Teresa é enviada por seu pai ao convento, na qual vemos a denúncia do narrador camiliano ao ambiente hipócrita e dissoluto das freiras. Nesse trecho, ele ironicamente afirma dar uma "amostra do evangélico e exemplar viver do convento onde Tadeu de Albuquerque mandara a sua filha a respirar o puríssimo ar dos anjos" (CASTELO BRANCO, 1984, p. 441). O efeito cômico é construído a partir dos diálogos das freiras com Teresa, nos quais elas se contradizem, pois cada uma aponta as "paixões do mundo" que a outra cultiva, sendo todas devassas - ou no campo amoroso, ou no abuso do álcool, por exemplo 
-, tendo um comportamento muito diverso do que se esperaria de uma religiosa, a começar pela intriga, algo que a madre prioresa garante não existir num convento: "Más-línguas é coisa que a menina não há-de achar aqui, nem intriguistas, nem murmurações de soalheiro" (CASTELO BRANCO, 1984, p. 438).

Após o narrador ironicamente retratar que as freiras horrorizaram-se por Teresa suspirar pela "liberdade do coração", "como se ouvissem na palavra 'coração' uma heresia, uma blasfêmia proferida na casa do Senhor” (CASTELO BRANCO, 1984, p. 436-437), temos destilados através da voz das personagens exemplos de libertinagem. Logo depois de a mestra de noviças ter relatado que a madre prioresa, "enquanto foi nova, era a freira que mais escândalos dava na casa; depois de velha era a mais ridícula, porque ainda queria amar e ser amada; agora, que está decrépita, anda sempre este monstrengo a fazer missões, e a curar indigestões" (CASTELO BRANCO, 1984, p. 438), a prioresa assim a define: "apesar de ser mestra de noviças à falta doutra que quisesse sê-lo, se eu lhe não andasse com o olho em cima, estragava-me as raparigas" (CASTELO BRANCO, 1984, p. 439). Já a escrivã tinha o defeito de "tomar da pingoleta; depois, não há quem a ature $[\ldots .$.$] , gasta tudo em vinho, e tem ocasiões de entrar no coro a fazer ss, que é mesmo uma$ desgraça [...]; tem sempre uns namorados pandilhas que bebem com ela na grade [...]" (CASTELO BRANCO, 1984, p. 439, grifo do autor); o narrador camiliano denomina-a ironicamente "Dionísia da Imaculada Conceição", em clara referência a Dioniso, deus do vinho, reforçando o tom cômico da passagem.

Em outro capítulo, dirigindo-se ao convento para entregar uma carta de Simão a Teresa, Mariana é cortejada por um padre, em mais um momento cômico de crítica anticlerical, com expressões irônicas do narrador, destacadas por nós:

- Que boa moça! - disse o padre capelão, que estava no raro lateral da porta, praticando com a prioresa, acerca da salvação das almas, e dumas ancoretas de vinho do Pinhão, que ele recebera naquele dia, e do qual já tinha engarrafado um almude para tonizar o estômago da prelada.

- Que boa moça! - tornou ele, com um olho nela e outro no raro, onde a ciumosa prioresa se estava remordendo.

- Deixe lá a moça, e diga quando há-de ir a servente buscar o vinho.

- Quando quiser, Senhora Prioresa; mas repare bem nos olhos, no feitio, naquele todo da rapariga!

- Pois repare o Senhor padre João - replicou a freira -, que eu tenho mais que fazer.

E retirou-se com o coração malferido, e o queixo superior escorrendo lágrimas... de simonte. (CASTELO BRANCO, 1984, p. 458-459, grifos nossos)

Acerca desse convento, Esther de Lemos afirma que "Teresa sofre menos ali: é que a pintura jocosa do ambiente distrai o narrador, o leitor e a própria personagem, do drama passional em que todos estavam empenhados" (LEMOS, 1992, p. 25). António Cabral, por sua vez, define a cena do "padre capelão galanteador" como "um balde de água fria no significado da clausura de Teresa" (CABRAL, 1993, p. 59).

O crítico também aponta o capítulo XVI - caracterizado ironicamente pelo narrador como não sendo "muito concertado com o seguimento da história" (CASTELO BRANCO, 1984, p. 504) - como mais um "exemplo de interrupção lúcida e lúdica do clima patológico crescente” (CABRAL, 1993, p. 59). Ora, se a passagem está presente no romance, é porque nele cumpre uma função, ainda que não claramente expressa. Esse 
capítulo conta a aventura amorosa do irmão de Simão, Manuel Botelho, que passa a viver com uma açoriana casada com um estudante de medicina. O pai de Simão, devido à acusação de Manuel ter desertado da Cavalaria, resolve intervir no caso e manda a amante de seu filho de volta aos Açores.

O episódio não é trágico, uma vez que todos acabam bem - o que se contrapõe à tragédia passional de Simão e Teresa. A açoriana voltou "para a sua terra, e para o abrigo de sua mãe, que a julgara morta, e lhe deu anos de vida, se não ditosa, sossegada e desiludida de quimeras" (CASTELO BRANCO, 1984, p. 509-510). Manuel, por sua vez, "obtido o perdão pela preponderância do corregedor do crime, mudou de regimento para Lisboa, e aí permaneceu até que, falecido o pai, pediu a baixa e voltou à província" (CASTELO BRANCO, 1984, p. 510). No meio de seu relato, o narrador insere um suposto aparte do narratário, para em seguida expor a sua opinião:

Poucas horas depois, a esposa do médico...

- Que tinha morrido de paixão e vergonha, talvez! - exclama uma leitora sensível.

- Não, minha Senhora; o estudante continuava nesse ano a freqüentar a Universidade; e como tinha já vasta instrução em Patologia, poupou-se à morte da vergonha, que é uma morte inventada pelo visconde de Almeida Garrett no Frei Luís de Sousa, e à morte da paixão, que é outra morte inventada pelos namorados nas cartas despeitosas, e que não pega nos maridos a quem o século dotou de uns longes de filosofia, filosofia grega e romana, porque bem o sabem que os filósofos da Antigüidade davam por mimo as mulheres aos seus amigos, quando os seus amigos por favor não lhas tiravam. E esta filosofia hoje então... Pois o médico não morreu, nem sequer desmedrou ou levou $R$ significativo de preocupação do ânimo insensível às amenidades da terapêutica. (CASTELO BRANCO, 1984, p. 508-509, grifo do autor)

Percebemos que, nesse trecho, o narrador desvela não apenas a falsidade da literatura romântica, exemplificada aqui por Garrett, mas a do próprio mote de Amor de Perdição, que é contado a partir das cartas escritas pelo casal de protagonistas. Como afirma Óscar Lopes, temos nesse capítulo "um remoque ao visconde de Almeida Garrett, a propósito de uma ridicularização de certas mortes românticas melodramáticas que, com pequenos retoques, bem se aplicariam ao próprio Amor de Perdição" (LOPES, 2007, p. 79). É interessante também notarmos a presença de uma nota de rodapé que reforça o tom cômico e que, junto com o final não trágico da aventura amorosa de Manuel Botelho, mostra uma perspectiva, de certa forma, realista da vida e muito diferente da dramaticidade da história de Simão e Teresa:

Vou lhes contar um lance memorando dum filósofo da atualidade [...]. Hoje (21 de Setembro de 1861) estava eu no escritório do ilustre advogado Joaquim Marcelino de Matos, e um cliente entrou contando o seguinte: - "Senhor Doutor, eu sou um lojista da Rua de...; e fui roubado em oitocentos mil réis por minha mulher, que fugiu com um amante para Viana. Venho saber se posso querelar, e receber o meu dinheiro." - "Pode querelar", respondeu o advogado, "se tiver testemunhas. O Senhor quer querelar por adultério?" Responde o queixoso: "O que eu quero é o meu dinheiro." - "Mas”, redargúi o consultor, "o Senhor pode querelar de ambos, dela por adúltera, e dele como receptador do furto." - "E receberei o meu dinheiro?" - "Conforme. Eu sei cá se ele tem o seu dinheiro?! O que sei é que não pode pronunciá-la a ela como ladra." - "Mas os meus oitocentos mil réis?!” - "Ah! o Senhor não se lhe dá que sua mulher fuja e não volte?" - "Não, Senhor Doutor, que a leve o Diabo; 
o que eu quero é o meu dinheiro." - "Pois quer ele de ambos e veremos depois." - "Mas não é certo receber eu o meu dinheiro?!” - “Certo não é; veremos se, depois de pronunciado, as autoridades administrativas capturam o ladrão com o seu dinheiro." - "E se ele o não tiver já?” - redargúi o marido, consternado. - "Se o não tiver já, o Senhor vinga-se na querela por adultério." - "E gasta-se alguma coisa?" - "Gasta, sim; mas vinga-se.” - "O que eu queria era o meu dinheiro, Senhor Doutor; a mulher deixá-la ir, que tem cinqüenta anos." - "Cinqüenta anos!", acudiu o doutor, "o Senhor está vingado do amante. Vá para casa, deixe-se de querelas, que o mais desgraçado é ele.” (CASTELO BRANCO, 1984, p. 508-509)

Segundo Cabral, “a pausa não tem apenas uma função relaxante: proporciona também as condições necessárias a uma observação objetiva, desafetada. É o criador a abandonar de certa maneira a sua criatura" (CABRAL, 1993, p. 59-60). Há um romance camiliano, no entanto, em que tal procedimento literário é onipresente: O Que Fažem Mulheres, obra menos conhecida, de definição controversa, mas considerada por Cleonice Berardinelli um "[...] exemplário privilegiado, paradigma, espelho de aumento" (BERARDINELLI, 1994, p. 235) da ficção camiliana.

O romance conta a história de Ludovina, moça bela, porém sem dote, que após uma desilusão amorosa resolve ceder às chantagens do pai, Melchior Pimenta, e aos conselhos da mãe, Angélica, e casa-se com João José Dias, um brasileiro de torna-viagem rico, porém velho, feio e excessivamente gordo. No decorrer da trama, João José Dias começa a ter acessos de ciúmes, e tenta matar o homem que julgava ser o amante de sua esposa. Este, no entanto, era amante de Angélica, e depois descobrimos ser o verdadeiro pai de Ludovina. A moça, contudo, resolve assumir a culpa pela sua mãe - apesar de o brasileiro ter descoberto a verdade, tendo enlouquecido de remorsos por julgar ter assassinado um homem injustamente - e interna-se num convento, na condição de adúltera, acompanhada por Angélica.

Em O Que Faz̧em Mulheres, as intrusões cômicas do narrador camiliano aparecem a todo o momento, como Berardinelli explicou: “o livro tem páginas repassadas de emoção, situações dramáticas, reflexões enternecidas, diálogos tensos, mas a tensão do leitor se afrouxa, a lágrima seca, ao som da voz do narrador” (BERARDINELLI, 1994, p. 235). Como exemplos, podemos citar as cenas de fúria ciumenta de João José Dias, nas quais o narrador insere descrições grotescas do personagem, que quebram a tensão através do cômico:

Mas o interior de João José? Era um incêndio para que a filosofia humana não inventou ainda bomba eficaz! Era o inferno do moiro de Veneza chorriscando aquele humano torresmo! (CASTELO BRANCO, 1983, p. 1281)

Fazia medo a cara do homem. Esverdinharam-se os rôfegos da papeira; as ventas fumegavam soluçando; testa e pálpebras, tinham o escarlate da penca do peru assanhado. (CASTELO BRANCO, 1983, 1289)

Numa das passagens em que o brasileiro tem um acesso de ciúme, Melchior Pimenta vai contar o ocorrido a Angélica, que havia lhe dito que tinha ido dormir com dor de cabeça, e encontra a esposa ainda vestida. Ela, porém, explica que a dor era tanta que 
"nem forças tive para desapertar os colchetes" (CASTELO BRANCO, 1983, p. 1287). Após esse diálogo, encontramos três linhas de reticências, utilizadas de maneira paródica, seguidas de um comentário do narrador:

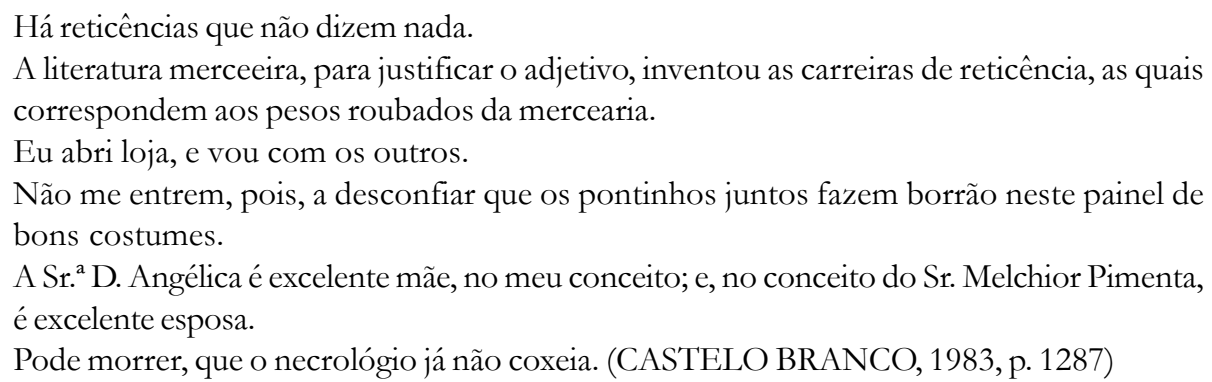

Assim, o narrador camiliano parodia o uso de reticências pela literatura romântica, acrescentando uma autocrítica irônica, na qual acusa os autores de encherem linhas para aumentarem a sua obra e, com isso, ganharem mais dinheiro, uma vez que os folhetinistas da época recebiam, muitas vezes, por linha escrita. Além disso, através desse comentário, o narrador ridiculariza a cegueira de Melchior Pimenta, pois, como o leitor já sabe, Angélica ainda estava vestida porque estava na companhia do amante. O marido traído também é alvo de zombaria na passagem em que é flagrado dormindo profundamente, enquanto Ludovina discute com o brasileiro, procurando convencê-lo de que a adúltera era ela, apesar de ele ter ouvido a conversa entre mãe e filha, e, portanto, saber da traição de sua sogra:

Melchior Pimenta, no quarto imediato, espreguiçando-se fazia com os abrimentos de boca
uma toada em falsete, ríspida como o uivar do mastim. Abençoados quatro grãos de morfina
que lhe povoastes o sono de deleitosas visões! Melchior Pimenta, eu, quando quero fantasiar
um marido bem-aventurado, lembras-me tu. (CASTELO BRANCO, 1983, p. 1300)

Já o tom excessivamente "lagrimoso" do capítulo em que Ludovina visita o amante de sua mãe, moribundo após ter sido baleado pelo brasileiro, e descobre que este é seu pai - e não Pimenta -, é interrompido pelo tom cômico do capítulo seguinte. Denominado “Cinco páginas que é melhor não lerem”, ele consiste numa paródia do linguajar jurídico, a fim de contradizer a lei do Digesto de que "O pai é aquele que se diz pai no assento do batismo" (CASTELO BRANCO, 1983, p. 1324) e defender a obviedade da afirmação "Pai é aquele que é pai" (CASTELO BRANCO, 1983, p. 1325). Esse trecho termina com o paródico "Corolário": "Melchior Pimenta era um dois pais presumidos na intenção do Digesto, na lei citada, do L. $5^{\circ}$. de in jus voc., e C. da Rocha no cap. Paternidade e filiação legítima" (CASTELO BRANCO, 1983, p. 1327, grifo do autor).

Ao fim do penúltimo capítulo, o narrador apresenta, através de um discurso paródico erigido pelo que ele chama de uma "imaginação de empréstimo", uma crítica irônica aos escritores de folhetins melodramáticos, que exploram histórias trágicas e sangrentas, mostrando a sua distância perante esse tipo de literatura, que não prima pelo real: 
Estes amores de António de Almeida e D. Angélica, tratados por imaginação de mais pulso, davam para muito brilhar. Estou a vê-lo a ele, pelo prisma fantástico dos mestres, erguer-se da cama com a mecha ainda na aberta chaga, um par de pistolas de doze tiros na algibeira, entrar, de cabelos hirtos e rosto lívido, no quarto de Angélica, e semi-desfalecido nos braços dela, dar largas à parlenda, e vociferar, por entre amorosas frases, esconjúrios odientos contra o gênero humano, contra a instituição do matrimônio, e contra os deveres conjugais! Agora se me afigura ver Melchior Pimenta no limiar da porta, e embasbacar petrificado diante do grupo escandaloso. Há gritos, injúrias, investidas, até que alfim, levados à puridade para um recanto da casa, aí combinam um duelo de morte, no dia seguinte. Medonha figuração me avulta agora na imaginação de empréstimo. Melchior Pimenta, após a detonação de dois tiros, cambaleia sobre as pernas, leva a mão ao seio que espirra golfos de sangue, põe os olhos anuviados no céu impassível, que contempla o quadro feio, e expede o derradeiro hálito, nos braços dos padrinhos.

Quantos capitulos desgrenhados cuida o leitor que dava esta parvoiçada imaginativa? Dois volumes em oitavo com seiscentas páginas, afora o subsídio das reticências, que, na minha opinião doutro tempo, foram inventadas para definir a mulher; e, na minha opinião de agora, inventou-as o primeiro literatiço oco de idéias. (CASTELO BRANCO, 1983, p. 1340, grifos nossos)

Propositadamente contrastando com esse falso desenlace, no final do romance, quando Angélica revela a Melchior Pimenta ser ela a adúltera, o narrador parodia a maneira trágica e patética com que os folhetins românticos exploram a descoberta de um adultério, apresentando uma atitude oposta do marido traído, quebrando o clímax que poderia ser suscitado:

Melchior Pimenta saiu do quarto de sua mulher.

Para se armar do punhal de D. Jaime de Bragança, e do infante D. João?

Para se dar um tiro no ouvido?

Para mergulhar da ponte-pênsil, ou despenhar-se dos Arcos das Virtudes?

Para cismar e endoidecer?

Não, senhores.

Melchior Pimenta foi para a Alfândega, jantou no hotel de Miss Mery, e jogou o voltarete até as onze horas na Assembléia Portuense. (CASTELO BRANCO, 1983, p. 1347)

O narrador termina o seu relato contando que tanto o marido de Angélica quanto o seu amante acabam a história bem: "Melchior Pimenta está bom, e é comensal do barão. António de Almeida encetou, há dois anos, uma longa viagem donde não voltou ainda" (CASTELO BRANCO, 1983, p. 1347).

Como afirma João Bigotte Chorão, "Camilo tem esse segredo de, nos lances mais dramáticos, introduzir uma situação ou observação caricatural, uma digressão inesperada no contexto, que servem a atenuar a tensão, a dar ânimo ao leitor, quando menos espera ser sacudido por frouxos de riso" (CHORÃO, 1990, p. 44). Dessa forma, parece-nos que esses romances, antes de suscitarem emoções gratuitas, através de peripécias melodramáticas, conduzem à reflexão. Segundo António Cabral, temos em Camilo "divertimento e ensinamento ${ }^{1}$, como no teatro épico de Bertolt Brecht" (CABRAL, 1993, p. 54). A analogia feita entre Brecht e Camilo não nos parece absurda ${ }^{2}$, se desconsiderarmos as diferenças entre os gêneros - romance e teatro - e atentarmos apenas aos recursos literários utilizados por ambos em suas obras. 
Anatol Rosenfeld explicou, a partir das palavras de Brecht, que "o teatro épico não combate as emoções [...]. Examina-as, e não se satisfaz com a sua mera produção" (ROSENFELD, 2006, p. 148). Segundo o teórico, o teatro épico pretendia combater a alienação provocada pela catarse dramática, elevando a emoção ao raciocínio através do efeito de distanciamento, que torna estranho ao espectador aquilo que lhe é habitual, "[...] para que nós mesmos e a nossa situação se tornem objetos do nosso juízo crítico" (ROSENFELD, 2006, p. 151). Ele aponta alguns recursos literários utilizados por Brecht para a construção desse efeito de distanciamento: "ao lado da atitude narrativa geral associada à própria estrutura da peça, Brecht emprega, para obter o efeito desejado, particularmente a ironia. 'Ironia é distância', disse Thomas Mann. [...] Outro recurso é a paródia” (ROSENFELD, 2006, p. 156).

Como vimos através das análises de Amor de Perdição e O Que Faz̧em Mulheres, algumas das características que mais se sobressaem nesses romances são a onipresença do narrador, que insere seus comentários irônicos a todo momento da ação, e a utilização sistemática da paródia, como forma de rebaixar os personagens e desconstruir os discursos literários vigentes. Com isso, temos o impedimento da completa fruição da tensão dramática, promovendo, assim, a reflexão, tanto sobre os modelos em voga, como sobre os comportamentos sociais.

É importante, no entanto, ressaltarmos aqui uma das muitas diferenças entre Brecht e Camilo. O dramaturgo, pertencente a outro contexto histórico, político e social, pós-Revolução Russa, tinha um claro propósito de fazer de sua arte um instrumento engajado de luta política, em defesa dos princípios marxistas, e sua oposição ao teatro dramático é motivada por um intuito didático de "apresentar um 'palco científico' capaz de esclarecer o público sobre a sociedade e a necessidade de transformá-la; capaz ao mesmo tempo de ativar o público, de nele suscitar a ação transformadora" (ROSENFELD, 2006, p. 148).

Camilo, por outro lado, não parece ter esse intuito didático, como deixa explícito nas palavras finais de $A$ Queda dum Anjo - "Fica sendo, portanto, esta coisa uma novela que não há-de levar ao céu número de almas mais vantajoso que o do ano passado" (CASTELO BRANCO, 1986, p. 1005) - e de A Brasileira de Prazins: "o meu romance não pretende reorganizar coisa nenhuma. E o autor desta obra estéril assevera, em nome do patriarca Voltaire, que deixaremos este mundo tolo e mau, tal qual era quando cá entramos" (CASTELO BRANCO, 1988, p. 852, grifo do autor).

Como vimos no final de $O$ Que Fazem Mulheres, apesar de todo o sofrimento pelo qual as personagens femininas passam, as personagens masculinas acabam bem, e o narrador nem sequer apresenta um comentário negativo. Em Amor de Perdição, por sua vez, o personagem que vive bem é Manuel Botelho, aquele que não se "deixou perder" por amor, que manteve os seus pés na realidade e soube viver de acordo com as regras da sociedade - é importante aqui ressaltarmos que o irmão de Simão não é visto de forma negativa pelo narrador, uma vez que, segundo afirma o final do romance, é "pai do autor deste livro" (CASTELO BRANCO, 1984, p. 539).

De acordo com João Bigotte Chorão, "Camilo não tem ilusões sobre o homem e a sociedade, e não cura pois de reformar nem um nem outra” (CHORÃO, 1993, p. 14). 
Com isso, segundo Maria Helena Nery Garcez, “[...] a ficção camiliana demonstra-se cética, não pretendendo desempenhar qualquer função moralizante ou educativa na vida social” (GARCEZ, 1992, p. 23). Concordamos com Carlos Reis e Maria da Natividade Pires, que afirmam que

é ainda a ironia que está presente quando o narrador demonstra preocupação com a função moralizante da literatura e verifica que não consegue que ela cumpra essa função porque a vida, afinal, não o permite [...]. Ele assume [...] uma posição ambígua, construindo muitos dos seus romances ou novelas segundo esse esquema "moralizador", mas tecendo com freqüência, nas margens do texto, comentários sobre a ineficácia da intervenção do romance na sociedade e sobre os exemplos falhos de "sã moralidade" que a própria vida dá. (REIS; PIRES, 1999, p. 220).

No entanto, apesar das diferenças programáticas entre Brecht e Camilo, é possível depreendermos que ambos chamam o leitor a ter uma atitude distanciada perante a matéria narrada: ele não deve se deixar arrebatar pelo "movimento inexorável" da catarse ou da tensão dramática, mas sim “observar, criticar, estudar" a situação apresentada. Sendo assim, podemos concluir que Camilo pressupunha dois tipos de leitores, como afirma no prefácio "A todos os que lerem”, de O Que Fazem Mulheres: “O leitor, esse precisa mais alguma coisa: inteligência; - e, se não bastar esta, valha-se da resignação" (CASTELO BRANCO, 1983, p. 1233).

Para esse leitor menos inteligente - o que se valeria da resignação -, o autor apresentava as ações mirabolantes e situações patéticas do folhetim melodramático. Para aquele provido de inteligência - "a 'audiência' que perceb[e] o jogo [...], sempre uma audiência de certo modo privilegiada” (FERRAZ, 1985, p. 26) -, Camilo escrevia as entrelinhas da narrativa, repletas de ironia e paródia a esses mesmos procedimentos folhetinescos. Com isso, agradava a todos e garantia, assim, o sucesso comercial de seus livros. Até os dias de hoje. ${ }^{3}$

\section{Notas}

\footnotetext{
${ }^{1}$ Deixamos aqui a ressalva de que não concordamos plenamente com o termo “ensinamento".

${ }^{2}$ Talvez seja pertinente lembrarmos que António José Saraiva fez um interessante estudo sobre o "forte cunho épico de parte da obra de Gil Vicente", considerado pelo crítico "um predecessor remoto e eficaz" do efeito de distanciamento utilizado por Brecht (ROSENFELD, 2006, p. 57). Este estudo pode ser encontrado no capítulo denominado "Gil Vicente e Bertolt Brecht", presente em seu livro Para a História da Cultura em Portugal. ${ }^{3}$ Agradeço à Fundação de Amparo à Pesquisa do Estado de São Paulo (FAPESP) pelo apoio dado à pesquisa intitulada "Entre o coração e o estômago: o olhar distanciado de Camilo Castelo Branco", da qual este artigo faz parte.
}

\section{Bibliografia}

BERARDINELLI, Cleonice. "Pela mão do narrador". Actas do Congresso Internacional de Estudos Camilianos. Coimbra: Comissão Nacional das Comemorações Camilianas, 1994, p. 223-236. 
BRAGA, Teófilo. As Modernas Idéias na Literatura Portuguesa. Porto: Lugan \& Genelioux, 1892.

CABRAL, António. "A técnica da distanciação em Camilo". Estudos Camilianos: Camilo Castelo Branco - Jornalismo e Literatura no Século XIX. Braga: n. 3, 1993, p. 51-60.

CARVALHO, João Soares. "O segundo romantismo: considerações contextuais". In: MACHADO, Álvaro Manuel et al. História da Literatura Portuguesa. $4^{\circ}$ v. Mem Martins: Publicações Alfa, 2003, p. 237-253.

CASTELO BRANCO, Camilo. Amor de Perdição: memórias de uma família. In: Obras Completas. $3^{\circ}$ vol. Porto: Lello \& Irmão, 1984, p. 373-547.

. A Brasileira de Prazins: cenas do Minho. In: Obras Completas. $8^{\circ}$ vol. Porto: Lello \& Irmão, 1988, p. 675-857.

. O Que Fazem Mulheres: romance filosófico. In: Obras Completas. $2^{\circ}$ vol. Porto: Lello \& Irmão, 1983, p. 1227-1372.

. A Queda dum Anjo. In: Obras Completas. 5 vol. Porto: Lello \& Irmão, 1986, p. 833-1025.

CHORÃO, João Bigotte. "Nótulas sobre jornalismo literário no século XIX". Estudos Camilianos: Camilo Castelo Branco - Jornalismo e Literatura no Século XIX. Braga: n. 3, 1993, p. 13-18.

. Páginas Camilianas e Outros Temas Oitocentistas. Lisboa: Guimarães, 1990.

COELHO, Jacinto do Prado. Introdução ao Estudo da Novela Camiliana. $3^{\mathrm{a}}$ ed. Lisboa: Imprensa Nacional/Casa da Moeda, 2001.

FERRAZ, Maria de Lourdes A. A Ironia Romântica: estudo de um processo comunicativo. Lisboa: Imprensa Nacional/Casa da Moeda, 1985.

FIGUEIREDO, Fidelino de. Literatura Portuguesa: desenvolvimento histórico das origens à atualidade. Rio de Janeiro: Noite, 1941.

FRANCHETTI, Paulo. Apresentação. In: CASTELO BRANCO, Camilo. Coração, Cabeça e Estômago. São Paulo: Martins Fontes, 2003, p. IX-L.

GARCEZ, Maria Helena Nery. Acerca das designações dos agentes em Amor de Perdição. In: Revista Colóquio/Letras. Lisboa: Calouste Gulbenkian, n. 125/126, jul. 1992, p. 15-24.

LEMOS, Esther de. Da casa à cela. In: BAPTISTA, Abel Barros et al (Orgs.). Camilo: Interpretações Modernas: antologia. Porto: Comissão Nacional das Comemorações Camilianas, 1992, p. 23-27.

LOPES, Óscar. Ensaios Camilianos. Porto: Fundação Eng. António de Almeida, 2007.

REIS, Carlos e PIRES, Maria da Natividade. História Crítica da Literatura Portuguesa: O Romantismo. $5^{\circ}$ vol., $2^{\text {a }}$ ed. Lisboa: Verbo, [1999].

ROSENFELD, Anatol. O Teatro Épico. $4^{\mathrm{a}}$ ed. São Paulo: Perspectiva, 2006.

SARAIVA, António José. Gil Vicente e Bertolt Brecht. In: Para a História da Cultura em Portugal. $2^{\circ}$ vol., $4^{a}$ ed. Lisboa: Publicações Europa-América, 1972, p. 309-325.

SARAIVA, António José; LOPES, Óscar. História da Literatura Portuguesa. $17^{\mathrm{a}}$ ed. Porto: Porto Editora, 1996.

TINHORÃO, José Ramos. Os Romances em Folhetins no Brasil: 1830 à atualidade. São Paulo: Duas Cidades, 1994. 